\title{
THE MANNICH-TYPE REACTION BETWEEN N,O-ACETALS AND CARBON NUCLEOPHILES UNDER SOLVENT-FREE CONDITIONS
}

\author{
Yoshihiro Matsumura, Takashi Ikeda, and Osamu Onomura \\ Department of Pharmaceutical Sciences, Graduate School of Biomedical Sciences, \\ Nagasaki University, 1-14 Bunkyo-machi, Nagasaki 852-8521, Japan
}

\begin{abstract}
The Mannich-type reaction for 1-methoxycarbonyl- or 1-benzyloxycarbonyl-2-methoxylpyrrolidine with carbon nucleophiles such as acetylacetone, methyl acetoacetate, dimethyl malonates, benzoylacetone, or dibenzoylmethane, or cyclohexane-1, 3-dione proceeded by acid catalysts under solvent-free conditions with more efficiently than that in dichloromethane.
\end{abstract}

The Mannich-type reactions between $\mathrm{N}$-acyliminium ions generated from $\mathrm{N}, \mathrm{O}$-acetals and nucleophiles have been frequently utilized to introduce substituents at the $\alpha$-position of various amines. ${ }^{1,2}$ We have already exploited some reactions between $\mathrm{N}, \mathrm{O}$-acetals prepared by electrochemical oxidation ${ }^{3}$ and various nucleophiles to afford some important $\alpha$-substituted amines. ${ }^{4}$ Those reactions were carried out in large volume of organic solvents which seemed to be environmentally unsuitable and uneconomical. ${ }^{5}$ So we examined solvent-free ${ }^{6}$ processes for such reactions, and found that the Mannich-type reaction for $\mathrm{N}, \mathrm{O}$-acetals (2a,b) proceeded though acyliminium ions under solvent-free conditions more efficiently than ones in organic solvents (Eq. 1). We report herein the detail of the results and the comparison with the corresponding reactions carried out using organic solvents.

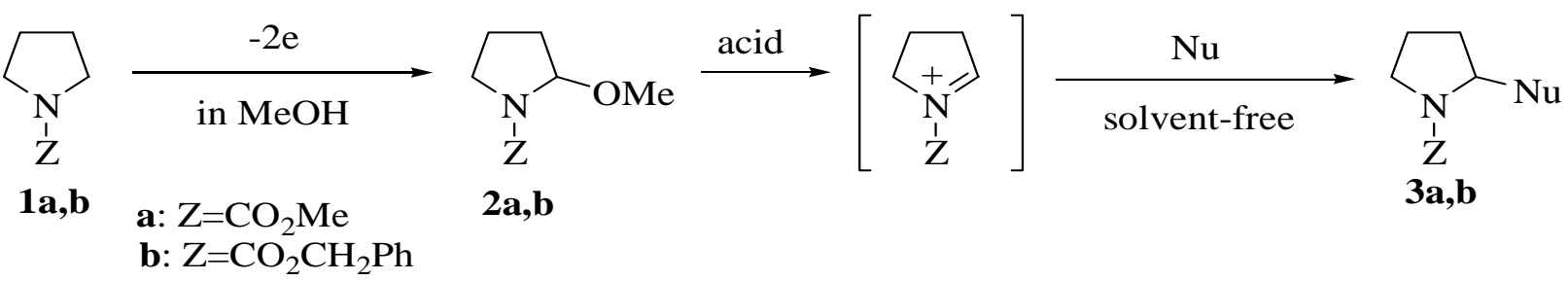

The preparation of 2a,b was easily achieved by electrochemical oxidation of 1-methoxycarbonyl- or benzyloxycarbonylpyrrolidines (1a,b) in methanol. ${ }^{2}$ With having 2a,b in our hand, we first examined the reactions of $\mathbf{2 a}$ with liquid active methylene compounds (4p-q) (3 equiv. to $2 \mathbf{a}){ }^{7-9}$ a kind of carbon nucleophiles, in the presence of a catalytic amount of some acids under solvent-free ${ }^{10}$ and solvent $\left(\mathrm{CH}_{2} \mathrm{Cl}_{2}\right)$ conditions to afford the products (3ap-ar) $)^{7}$ (Eq. 2). The results are summarized in Table 1 which shows the yields based on 2a. The yields depended on the reaction conditions. That is, the yields of the coupling product (3ap) in the case using acetylacetone (4p) under solvent-free conditions were much improved from ones under solvent conditions (entries 1-4), and the yields of 3aq and 3ar in the cases using acetoacetate (4q) and dimethyl malonate (4r) under solvent-free conditions were similar to or better than under solvent conditions.

\footnotetext{
* Corresponding author, Tel +81-95-819-2429, Fax+81-95-819-2476, E-mail matumura@net.nagasaki-u.ac.jp
} 


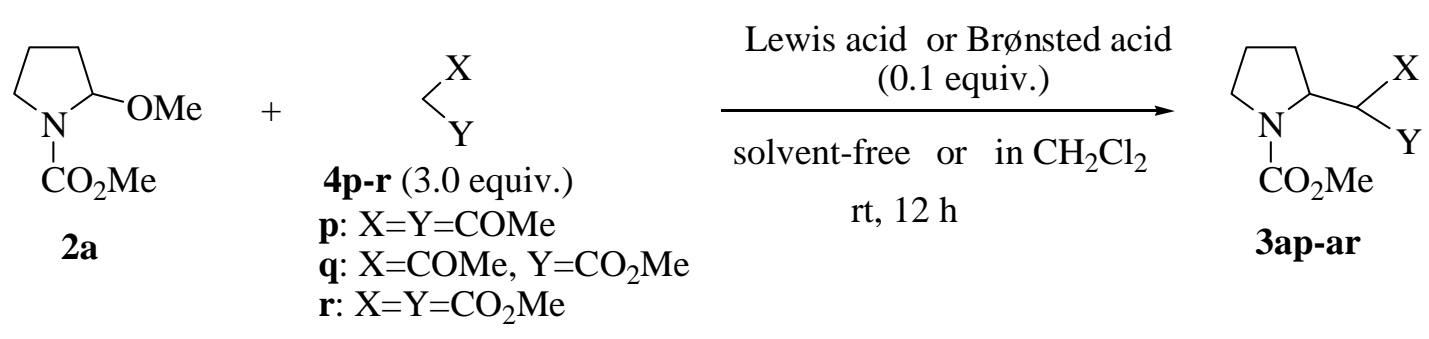

Table 1. Solvent-free and solvent reaction of $N, O$-acetal (2a) with active methylene compounds (4p-r) in the persence of acids

\begin{tabular}{|c|c|c|c|c|c|}
\hline \multirow[b]{2}{*}{ entry } & \multirow[b]{2}{*}{ nucleophile } & \multirow[b]{2}{*}{$\operatorname{acid}^{\mathrm{a}}$} & \multirow[b]{2}{*}{ product } & \multicolumn{2}{|c|}{ yield (\%) } \\
\hline & & & & solvent-free & in $\mathrm{CH}_{2} \mathrm{Cl}_{2}$ \\
\hline 1 & $4 p$ & $\mathrm{TiCl}_{4}$ & Зар & 89 & 70 \\
\hline 2 & $4 p$ & $\mathrm{TiCl}_{2}(\mathrm{O}-\mathrm{i}-\mathrm{Pr})_{2}$ & 3ap & 84 & $16^{\mathrm{d}}$ \\
\hline 3 & $4 p$ & $\mathrm{CF}_{3} \mathrm{SO}_{3} \mathrm{H}$ & Зар & 77 & 44 \\
\hline 4 & $4 p$ & $p$-TsOH & Зар & 94 & 67 \\
\hline 5 & $4 q$ & $\mathrm{TiCl}_{4}$ & $3 a^{c}$ & 93 & 87 \\
\hline 6 & $4 q$ & $\mathrm{TiCl}_{2}(\mathrm{O}-\mathrm{i}-\mathrm{Pr})_{2}$ & $3 \mathbf{a q}^{\mathrm{c}}$ & 87 & 94 \\
\hline 7 & $\mathbf{4 q}$ & $\mathrm{CF}_{3} \mathrm{SO}_{3} \mathrm{H}$ & $3 \mathbf{a q}^{\mathrm{c}}$ & 93 & 56 \\
\hline 8 & $4 q$ & $p$-TsOH & $3 \mathbf{a q}^{\mathrm{c}}$ & 74 & 61 \\
\hline 9 & $4 r$ & $\mathrm{TiCl}_{4}^{\mathrm{b}}$ & 3ar & 76 & 80 \\
\hline 10 & $4 r$ & $\mathrm{TiCl}_{2}(\mathrm{O}-\mathrm{i}-\mathrm{Pr})_{2}$ & 3ar & 61 & 57 \\
\hline 11 & $4 r$ & $p$-TsOH & 3ar & trace $^{\mathrm{c}}$ & trace $^{\mathrm{c}}$ \\
\hline
\end{tabular}

${ }^{\mathrm{a}} 0.1$ equiv. ${ }^{\mathrm{b}} \mathrm{Et}_{3} \mathrm{~N}\left(0.1\right.$ equiv) was added. ${ }^{\mathrm{C}}$ In all cases the ratios of diastereomer for product (3ap) were determined by HPLC to be about 2:1. ${ }^{\mathrm{d}}$ Conversions were very low.

Furthermore, we found that the coupling reaction of $2 \mathbf{a}$ with solid active methylene compounds (4s-u) was possible under solvent free conditions (Eq. 3), in which the amount of 2a was 3 equivalent to 1,3-diketones (4s-u) and the yields of the products (3as-3au) ${ }^{11}$ were obtained based on $4 \mathbf{s}$-u. The results indicate the advantage of solvent-free conditions in the Mannich-type reaction between 2a and 4s-u in comparison with the reaction in $\mathrm{CH}_{2} \mathrm{Cl}_{2}$ (Eq. 3).

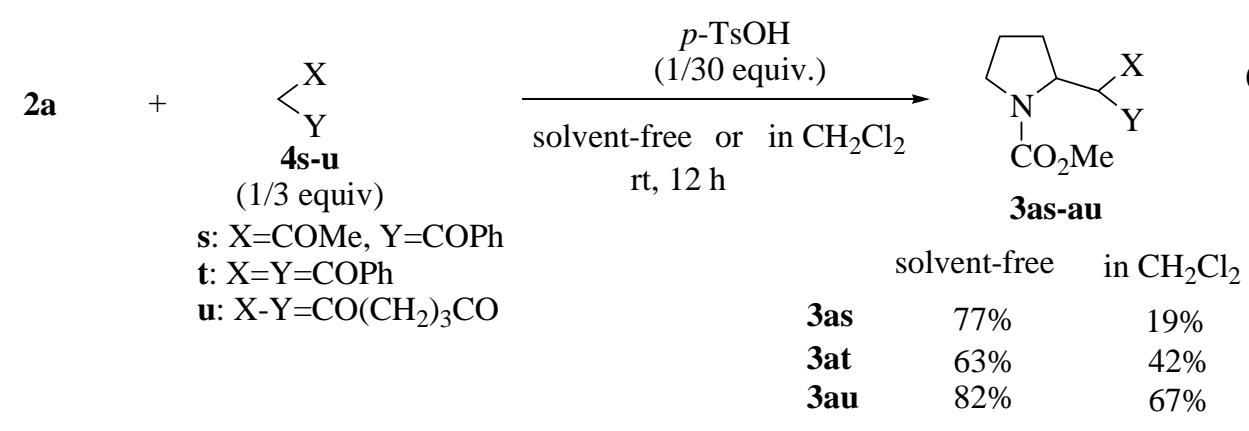

The solvent-free conditions were applicable to the Mannich-type reaction between $\mathrm{N}, \mathrm{O}$-acetal (2b) and 
$(\mathbf{4 p}, \mathbf{q}, \mathbf{t})$ to afford the coupling products (3bp, $\left.{ }^{11} \mathbf{b q},{ }^{8} \mathbf{b t}{ }^{11}\right)$ in good yields (Eq. 4).

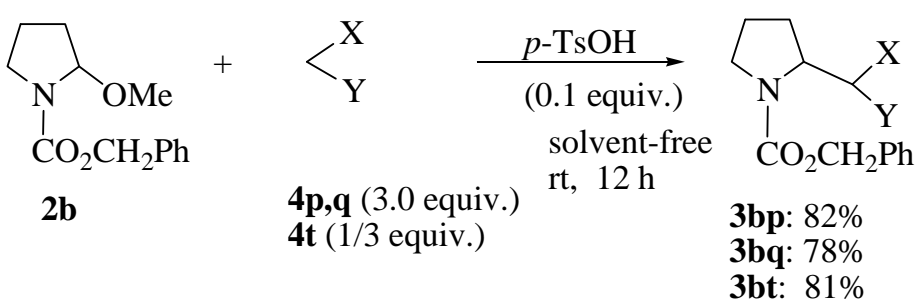

Furthermore, it was found that the yield (57\%) of $\mathbf{5}$ for the solvent-free allylation reaction ${ }^{12}$ of $\mathbf{2 a}$ was much superior to that (21\%) in $\mathrm{CH}_{2} \mathrm{Cl}_{2}$ (Eq. 5). In this type of reaction, interestingly, a chiral Lewis acid, $(S)$-BINOL-Ti complex, ${ }^{13}$ gave 5 with higher enantioselectivity (enriched isomer; $R$ ) under solvent-free conditions than that in $\mathrm{CH}_{2} \mathrm{Cl}_{2}$, though the ee's were very low. ${ }^{14}$

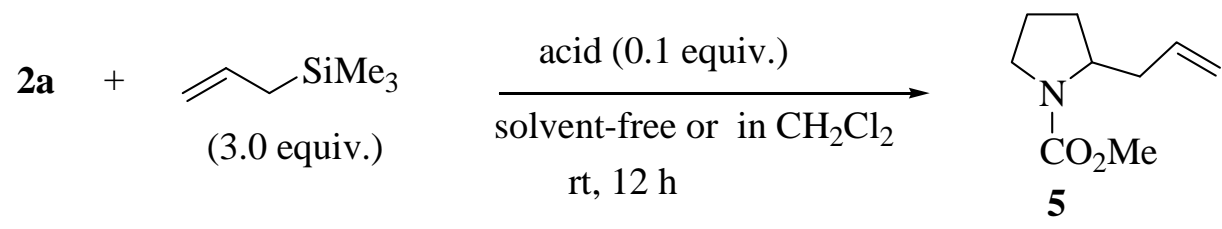

\begin{tabular}{ccc} 
acid & \multicolumn{2}{c}{ Yield (\%) of $\mathbf{5}$} \\
\cline { 2 - 3 } & solvent-free & in $\mathrm{CH}_{2} \mathrm{Cl}_{2}$ \\
\hline
\end{tabular}

Although there have not been any data to explain the reason why solvent-free conditions gave higher yields of products than those in $\mathrm{CH}_{2} \mathrm{Cl}_{2}$ in the Mannich-type reaction between $N, O$-acetals (2a,b) and carbon nucleophiles (4p-u), we presume that it might be resulted from faster trapping of $N$-acyliminium ions generated from 2a,b with $\mathbf{4 p - u}$ than that of reactions in $\mathrm{CH}_{2} \mathrm{Cl}_{2}$ because of high density of nucleophiles under solvent-free conditions.

In summary the Mannich-type reactions for $N, O$-acetals (2a,b) under solvent-free conditions proceeded more efficiently than ones in $\mathrm{CH}_{2} \mathrm{Cl}_{2}$. The characteristics and advantages of the Mannich-type reaction under solvent-free conditions will be applied into preparations of some biologically important $\alpha$-substituted cyclic amine derivatives.

\section{ACKNOWLEDGEMENT}

Y. M. and O.O. thank the Ministry of Education, Culture, Sports, Science and Technology, Japan for Scientific Research on Priority Areas, (No. 420: Reaction Control of Dynamic Complexes) and the Japan Society for the Promotion of Science for Scientific Research (C) (15550094).

\section{REFERENCES AND NOTES}

1. A recent review: W. N. Speckmap and M. J. Moolenaar, Tetrahedron, 2000, 56, 3817.

2. Some recent literatures, J. J. N. Veerman, J. Klein, R. W. N. Aben, H. W. Scheeren, C. G. Kruse, J. H. 
Van Maarseveen, F. P. J. T. Rutjes, and H. Hiemstra, Eur. J. Org. Chem., 2002, 3133; D. M. Andrews, A. D. Borthwick, H. Chaignot, P. S. Jones, J. E. Robinson, P. Shah, M. J. Slater, and R. J. Upton, Synthesis, 2003, 1722; U. Albrecht, H. Armbrust, and P. Langer, Synthesis, 2004, 143; A. C. Rudolph, R. Machauer, and S. F. Martin, Tetrahedron Lett., 2004, 45, 4895; T. Hjelmgaard, I. Sotofte, D. Tanner, J. Org. Chem. 2005, 70, 5688.

3. T. Shono, H. Hamaguchi, and Y. Matsumura, J. Am. Chem. Soc., 1975, 97, 4264; T. Shono, Y. Matsumura, and K. Tsubata, Org. Synth., Coll. Vol. 1990, VII, 307; G. N. Wanyoike, O. Onomura, T. Maki, and Y. Matsumura, Org. Lett., 2002, 4, 1875.

4. T. Shono, Y. Matsumura, O. Onomura, T. Kanazawa, and M. Habuka, Chem. Lett., 1984, 1101; Y. Matsumura, Y. Kanda, K. Shirai, O. Onomura, and T. Maki, Org. Lett., 1999, 1, 175; Y. Matsumura, Y. Kanda, K. Shirai, O. Onomura, and T. Maki, Tetrahedron, 2000, 56, 7411; O. Onomura, Y. Kanda, Y. Nakamura, T. Maki, and Y. Matsumura, Tetrahedron Lett., 2002, 43, 3229; Y. Matsumura, O. Onomura, H. Suzuki, S. Furukubo, T. Maki, and C.-J. Li, Tetrahedron Lett., 2003, 44, 5519.

5. P. T. Anastas and C. Warner, Green Chemistry, Theory and Practice; Oxford, 1998.

6. J. O. Metzger, Angew. Chem., Int. Ed. Engl., 1998, 37, 2975; R. S. Verma, Green Chem., 1999, 43; K. Tanaka and F. Toda, Chem. Rev., 2000, 100, 1025; J. Long, J. Hu, X. Shen, B. Ji, and K. Ding, J. Am. Chem. Soc., 2002, 124, 10; J.-C. Lee, C.-A. Tai, and S.-C. Hung, Tetrahedron Lett., 2002, 43, 851; A. McCluskey, P. J. Robinson, T. Hill, J. L. Scott, and J. K. Edwards, Tetrahedron Lett., 2002, 43, 3117; F. Y. Kwong, C. W. Lai, and K. S. Chan, Tetrahedron Lett., 2002, 43, 3537; H. Sharghi and M. Hosseini, Synthesis, 2002, 1057; P. C. Andrews, A. C. Peatt, and C. L. Raston, Tetrahedron Lett., 2004, 45, 243; H. Zachova, S. Man, M. Necas, M. Potacek, Eur. J. Org. Chem., 2005, 2548.; D. Xiao, L. Wang, X. Feng, Synlett, 2005, 1531; X. Zhang, S. Lu, Synlett, 2005, 1535.

7. T. Shono, Y. Matsumura, and K. Tsubata, J. Am. Chem. Soc., 1981, 103, 117.

8. S. Louwrier, A. Tuynman, and H. Hiemstra, Tetrahedron, 1996, 52, 2629.

9. T. Shono, Y. Matsumura, K. Uchida, K. Tsubata, and A. Makino, J. Org. Chem., 1984, 49, 300; T.

Shono, Y. Matsumura, M. Ogaki, and O. Onomura, Chem. Lett., 1987, 1447; T. Nagasaka, S. Nishida, S. Sugihara, T. Kawahara, K. Adachi, and F. Hamaguchi, Heterocycles, 1994, 39, 171; N. S. Camilo and R. A. Pilli, Tetrahedron Lett., 2004, 45, 2821.

10. A typical experimental procedure under solvent-free conditions: Under an aerobic atomosphere, to a mixture of $N, O$-acetal (2a) (1 mmol, $159 \mathrm{mg}$ ) and acetylacetone (4p) (3 mmol, $300 \mathrm{mg}$ ) was added $\mathrm{TiCl}_{4}(0.1 \mathrm{mmol}, 0.197 \mathrm{~mL})$ at room temperature. After stirring for $12 \mathrm{~h}$, the reaction mixture was chromatographed on silica gel (ethyl acetate: $n$-hexane=1:3) to afford 3ap in 89\% yield.

11. ${ }^{1} \mathrm{H}$ NMR $\left(\mathrm{CDCl}_{3}, \delta\right)$ spectral data of new compounds are shown below.

3as: $1.60-2.33(\mathrm{~m}, 4 \mathrm{H}), 2.19$ (s, 3H), 2.85-3.80 (m, 2H), 3.66 and 3.69 (2s, 3H), 4.30-4.40, 5.10-5.18 and 5.58-5.62 (3m, $1 \mathrm{H}), 4.65-4.80(\mathrm{~m}, 1 \mathrm{H}), 7.38-7.65(\mathrm{~m}, 3 \mathrm{H}), 7.82-8.11(\mathrm{~m}, 2 \mathrm{H})$.

3at: $1.62-1.82(\mathrm{~m}, 2 \mathrm{H}), 2.00-2.28(\mathrm{~m}, 1 \mathrm{H}), 2.35-2.48(\mathrm{~m}, 1 \mathrm{H}), 2.85-3.10(\mathrm{~m}, 1 \mathrm{H}), 3.25-3.50(\mathrm{~m}, 1 \mathrm{H})$, 3.58 and $3.61(2 \mathrm{~s}, 3 \mathrm{H}), 4.58-4.82(\mathrm{~m}, 1 \mathrm{H}), 5.78$ and $6.40(2 \mathrm{~d}, J=4.0$ and $4.0 \mathrm{~Hz}, 0.25 \mathrm{H}$ and $0.75 \mathrm{H})$, 7.38-7.62 (m, 6H), 7.85-8.05 (m, 4H).

3au: 1.49-2.63 (m, 10H), 3.40-3.80 (m, 5.5H), 4.69-4.78 (m, 1H), 10.78 (br s, 0.5H).

3bp: 1.78-2.30 (m, 4H), 2.17 (br s, 6H), 3.30-3.40 (m, 1H), 3.45-3.52 (m, 1H), 4.00-4.50 (m, $1 \mathrm{H}), 4.45$ (br s, 1H), 5.13 (br s, 2H), $7.36(\mathrm{~s}, 5 \mathrm{H})$.

3bt: $1.62-2.50(\mathrm{~m}, 4 \mathrm{H}), 2.90-3.00(\mathrm{~m}, 1 \mathrm{H}), 3.10-3.55(\mathrm{~m}, 1 \mathrm{H}), 4.60-4.75(\mathrm{~m}, 1 \mathrm{H}), 4.98-5.30$ (m, $2 \mathrm{H})$, 7.20-7.45 (m, 10H), 7.50-7.58 (m, 2H), 7.65-7.75 (m, 1H), 7.90-8.00 (m, 2H).

12. T. Shono, Y. Matsumura, K. Tsubata, and K. Uchida, J. Org. Chem., 1986, 51, 2590; T. Shono, Y. Matsumura, O. Onomura, and M. Sato, J. Org. Chem., 1988, 53, 4118.

13. K. Mikami and M. Terada, Tetrahedron, 1992, 48, 5671; K. Mikami, Y. Motoyama, and M. Terada, J. Am. Chem. Soc., 1994, 116, 2812.

14. The ee's were determined by a chiral HPLC method: Daicel Chiralcel OJ (4.6 mm $\phi, 25 \mathrm{~cm}), n$-hexane, flow rate: $1.0 \mathrm{~mL} / \mathrm{min}$, detection at $210 \mathrm{~nm}$, retention time: $10 \mathrm{~min}$ for $(R)-(+)$-isomer and $13 \mathrm{~min}$ for (S)-(-)-isomer. 